\title{
Pemetaan Jaringan Komunikasi Ekonomi Non Ekstraktif Di Desa Cintaratu, Kecamatan Parigi Kabupaten Pangandaran dan Aplikasi Business Model Canvas
}

\section{Mapping of Non-Extractive Economic Communication Networks in Cintaratu Village, Parigi District, Pangandaran Regency and Business Model Canvas Applications}

\author{
Jajang Gumilar ${ }^{1 *}$, R. Febriyanto Christi ${ }^{1}$, Bambang Kholiq Mutaqin ${ }^{2}$, Fujia Dwi Valentin ${ }^{3}$, Nabila Aulia Putri ${ }^{3}$, \\ Yessi Ainurrachman ${ }^{3}$, Niken Rizky Ayu ${ }^{3}$, Khilda Rosyidah ${ }^{3}$, Fadia Haaya Nuraini ${ }^{3}$
}

* Korespondensi Penulis:

Bambang Kholiq Mutaqin

E-mail: kholiq@unpad.ac.id

${ }^{1}$ Fakultas Peternakan Universitas

Padjadjaran, Sumedang

${ }^{2}$ Prodi Peternakan Kampus

Pangandaran, Universitas Padjadjaran,

Pangandaran

${ }^{3}$ Mahasiswa PSDKU Pangandaran,

Universitas Padjadjaran, Pangandaran

Submitted July 28, 2019.

Revised Aug 4, 2020.

Accepted Aug 25, 2020.

\section{Abstract}

Communication has a very important role in human life. Communication carried out in the business is known as economic communication. Economic communication networks in the community can be formed due to interactions in their business. Non-extractive Businesses in Cintaratu Village, need to be identified their communication networks and business models in order to they can be developed into better businesses. The method used was the analysis of communication networks and the used of Business Model Canvas. The analysis showed that in general, non-extractive businesses in the Cintaratu Village have not yet formed a communication network. Communication network was formed only in the KWT Binangkit group, with the actor and hubs being Mrs. Tati. Business Model of Cintaratu Village BUMDes had a mutually beneficial, easy, and facilitative value for consumers; channel through community, and direct selling; revenue streams from revenue sharing and store lease; key activities in the form of canteen lease and investment; key resources consist of employees, equipment, and business facilities; key partnerships in collaboration with the local government, contractors, Unpad, equipment stores, youth organization, Kompepar, Bank BRI; cost structures that are available for investment, working capital and operational value.

Keywords: Communication network, non-extractive economy, Pangandaran, business model canvas.

\section{Abstrak}

Komunikasi memiliki peran yang sangat penting dalam kehidupan umat manusia yang terbentuk antar individu dan kelompok akhirnya membentuk suatu jaringan. Komunikasi yang dilakukan pada dunia bisnis dikenal pula dengan komunikasi ekonomi. Jaringan komunikasi pada masyarakat dapat terbentuk karena interaksi yang terjadi pada usaha yang mereka lakukan. Usaha Non ekstraktif yang ada di Desa Cintaratu perlu diidentifikasi jaringan komunikasi dan model usahanya agar dapat dikembangkan menjadi usaha yang lebih baik lagi. Metode yang dilakukan adalah analisis jaringan komunikasi dan penggunaan model Bussines Model Canvas. Hasil analisis menunjukkan bahwa pada umumnya usaha non ekstraktif di Desa Cintaratu belum terbentuk jaringan komunikasinya. Jaringan komunikasi baru terbentuk di kelompok KWT Binangkit, dengan aktor dan hubs nya adalah Ibu Tati. Business Model BUMDes Desa Cintaratu memiliki value saling menguntungkan, mempermudah, dan fasilitatif bagi konsumen, channel melalui komunitas, dan direct selling. Revenue Streams dari presentase bagi hasil dan penyewaan toko. Key Activities berupa penyewaan kantin dan penanaman modal. Key Resources terdiri dari karyawan, perlengkapan, dan fasilitas usaha, Key Partnerships bekerjasama dengan Pemerintah Daerah, Kontraktor, Unpad, Toko peralatan, Karang Taruna, Kompepar, Bank BRI, Cost Structures yang ada adalah biaya investasi, modal kerja, dan operasionavalue.

Kata Kunci: Jaringan Komunikasi, Ekonomi Non Ekstraktif, Pangandaran, Business Model Canvas. 


\section{Pendahuluan}

Komunikasi memiliki peran yang sangat penting dalam kehidupan umat manusia. Manusia tidak mungkin dapat hidup sendiri karena manusia adalah makhluk sosial yang harus memenuhi kebutuhan hidupnya. Kebutuhan hidup manusia sangat beragam mulai dari kebutuhan primer, sekunder, tersier, kebutuhan jasmani, dan rohani (Muhammad, 2004; Mulyana, 2005). Oleh karena itu manusia menjalin relasi dengan orang lain mulai dari keluarga inti, keluarga besar, tetangga, teman, rekan kerja, kenalan, teman dalam berbagai kelompok lain. Selain dengan individu lain, manusia juga berhubungan dengan lembaga, perusahaan, dan organisasi lainnya (Tjiptono, 2008).

Komunikasi yang terbentuk antar individu dan kelompok akhirnya membentuk suatu jaringan. Manusia telah membentuk berbagai jaringan komunikasi dengan berbagai kepentingan. Jaringan yang terbentuk dapat kuat ataupun renggang tergantung pada jalinan ikatan komunikasi dengan jaringan anggota-anggotanya dalam jaringan tersebut. Jaringan komunikasi merupakan sebuah fenomena yang dapat ditemukan di semua level kehidupan manusia baik kehidupan sehari-hari maupun dalam dunia bisnis. Komunikasi yang dilakukan pada dunia bisnis dikenal pula dengan komunikasi ekonomi.

Jaringan komunikasi ekonomi pada masyarakat dapat terbentuk karena interaksi yang terjadi pada usaha yang mereka lakukan. Jaringan komunikasi yang terbentuk dapat berasal dari individu dengan individu, individu dengan usaha, individu dengan kelompok usaha, atau kelompok usaha dengan kelompok usaha lainnya (Kotler, 2002). Jaringan komunikasi yang ada dapat digunakan untuk melihat siapa pemuka pendapat atau opinion leader sehingga dapat diketahui siapa yang menjadi pusat pada jaringan komunikasi tersebut. Dalam sebuah jaringan komunikasi terdiri atas beberapa elemen penting diantaranya yaitu : (1) aktor (node) tidak selalu berupa individu, bisa juga organisasi, negara, institusi dan sebagainya (Scott, Baggio dan Cooper, 2008). (2) link (edge) relasi antar aktor yang dilambangkan dalam satu garis yang menghubungkan antar aktor, (3) komponen adalah pengelompokan aktor yang sekurangnya mempunya satu link dalam jaringan, (4) klik adalah pengelompokan aktor yang ditandai dengan adanya relasi antar aktor secara lengkap dan maksimal, (5) bridges adalah jembatan yang menghubungkan dua kelompok terpisah dalam suatu jaringan, (6) hubs adalah merujuk kepada aktor yang mempunyai koneksi paling banyak dalam jaringan (Golbeck, 2013), (7) cutpoints adalah aktor yang menjadi perekat dari jaringan, bila tidak ada aktor tersebut maka jaringan akan terpecah (Borgatti dan Dejody, 2013), (8) pemencil (isolate) adalah aktor yang tidak mempunyai satu pun link dengan aktor lain dalam jaringan.

Kegiatan ekonomi yang ada di pedesaan juga membentuk suatu jaringan komunikasi tertentu. Kegiatan ekonomi non ekstraktif yang menggunakan bahan baku berasal dari hasil pengolahan usaha lainnya tersebar luas di pedesaan, seperti halnya yang terdapat di Desa Cintaratu, Kecamatan Parigi, Kabupaten Pangandaran. Pemetaan jaringan komunikasi ekonomi menjadi hal yang penting untuk meningkatkan kesejahteraan masyarakat desa, khususnya masyarakat Desa Cinta Ratu (Mutaqin, $\mathrm{dkk}, 2020)$

Desa Cintaratu Kecamatan Parigi Kabupaten Pangandaran ini terletak lebih kurang $29 \mathrm{Km}$ dari obyek Wisata Pantai Pangandaran menuju ke arah selatan. Wilayah Desa Cintaratu berbatasan dengan desa-desa sebagai berikut : Sebelah Utara berbatasan dengan: Desa Selasari Kecamatan Parigi, Sebelah Selatan berbatasan dengan : Desa Cintakarya Kecamatan Parigi, Sebelah Timur berbatasan dengan : Desa Bojong Kecamatan Parigi, Sebelah Barat berbatasan dengan : Desa Selasari Kecamatan Parigi.Luas Desa ini mencapai $1.029 \mathrm{Ha}$, sebagian besar merupakan lahan sawah dan ladang 288,61 Ha, pemukiman $200 \mathrm{Ha}$, dan perkebunan rakyat 116,72 Ha. Desa Cintaratu terdiri dari 5 Dusun , 10 Rukun Warga, 34 Rukun Tetangga. Jumlah penduduk 3.266 jiwa yang terdiri atas 1.799 laki laki dan 1.818 perempuan, laju pertumbuhan penduduk $2-3 \%$ per tahun. Indeks Pembangunan Manusia (IPM) Desa Cintaratu mencapai 75,89, sesai dengan target IM Kabupaten Pangandaran, bahkan tahun-tahun sebelumnya dapat melebihi target IPM Kabupaten. Raihan nilai IPM tertinggi ditunjang oleh indeks pendidikan yang mencapai 87,69 . Indeks daya beli masyarakat Desa Cintaratu masih belum tergolong tinggi masih sekitar 75 . Oleh karena itu daya beli masyarakat masih perlu ditingkatkan agar kesejahteraan masyarakat semakin meningkat.

Peningkatan kesejahteraan masyarakat menjadi salah satu fokus pembangunan nasional. Salah satu upaya peningkatan kesejahteraan masyarakat dengan meningkatkan kegiatan perekonomian di masyarakat. Kabupaten 
pangandaran merupakan Kabupaten termuda di Provinsi Jawa Barat. Sebagian besar masyarakat Pangandaran sudah tergolong pada masyarakat tidak miskin, hal ini tercermin dari data yang dieluarkan oleh BPS bahwa masyarakat miskin di Pangandaran hanya $8,12 \%$.

Peningkatan kesejahteraan masyarakat didorong oleh berbagai kegiatan perekonomian yang ada di daerah tersebut. Keberadaan PSDKU Pangandaran yang terletak di Desa Cintaratu, Kecamatan, Parigi, Kabupaten Pangandaran harus menjadi salah satu pendorong untuk meningkatkan kesejahteraan masyarakat Kabupaten Pangandaran, khususnya di Desa Cintaratu. Untuk mendorong kesejahteraan masyarakat di Desa Cintaratu tentu diperlukan berbagai data agar program peningkatan kesejahteraan masyarakat di Desa Cintaratu dapat berjalan dengan baik, oleh karena itu perlu dilakukan pemetaan jaringan ekonomi non ekstraktif khususnya pada sumber-sumber usaha seperti usaha manufaktur, jasa, dan perdagangan yang ada di Wiayah Desa Cintaratu, Kecamatan Parigi, Kabupaten Pangandaran (Nusantara, 2017).

Kegiatan PKM ini adalah untuk membantu memetakan jaringan komunikasi bisnis non ekstraktif; mengidentifikasi aktor, tokoh, bridge, isolate, struktur jaringan komunikasi bisnis non ekstraktif para pelaku usaha; mengidentifikasi potensi jaringan, sumberdaya manusia dalam percepatan diseminasi informasi pada masyarakat Desa Cintaratu. Manfaat yang dapat diperoleh dari kegiatan ini adalah terpetakannya jaringan komunikasi non ektraktif dan teridentifikasinya aktor, tokoh, isolate, struktur jaringan komunikasi bisnis non ekstraktif para pelaku usaha; serta dapat teridentifikasinya potensi jaringan sumber daya manusia dalam percepatan diseminasi informasi pada masyarakat Desa Cintaraatu.

\section{Materi dan Metode Pelaksanaan}

Data yang diperlukan dalam kegiatan PKM ini didapat dengan cara observasi lapangan untuk mengumpulkan dan mengidentifikasi data serta melakukan kegiatan lokakarya awal, mega event, dan lokakarya akhir. Data yang diperoleh dianalisis terlebih dahulu kemudian diserahkan kepada Pemerintah Desa Cintaratu sehingga dapat dijadikan data terbaru oleh Desa Cintaratu yang dapat digunakan untuk mencari solusi-solusi untuk meningkatkan kesejahteraan masyarakat Desa Cintaratu, Kecamatan Parigi, Kabuaten
Pangandaran.

Pengumpulan data diintegrasikan dengan program kegiatan KKN Kewirausahaan \& PPM PSDKU Unpad Pangandaran 2020 dilaksanakan pada 9 Januari - 12 Februari 2020 yang bertempat di Desa Cintaratu, Kecamatan Parigi, Kabupaten Pangandaran, Provinsi Jawa Barat dengan sasaran mengetahui serta memetakan potensi - potensi bisnis dan membantu menegaskan visi misi desa yang kemudian nantinya dapat menjadi acuan untuk pengembangan Desa Cintaratu. Adapun kegiatan yang laksanakan antara lain survey, wawancara dan pendataan potensi untuk mengetahui berbagai faktor yang dapat mempengaruhi masyarakat, serta mengidentifikasi permasalahan yang dihadapi oleh Desa Cintaratu, maka digunakanlah metode penelitian kualitatif.

Mekanisme kerja kelompok dibagi menjadi 3 tahapan yaitu persiapan, pelaksanaan dan output. Pada tahapan persiapan dilakukan pengarah tim terkait dengan Jaringan Komunikasi Industri Ekonomi Non-Ekstraktif (Perdagangan, Jasa dan Manufaktur) yang ada di Desa Cintaratu.

Pengumpulan data Jaringan Komunikasi Industri Ekonomi Non-Ekstraktif, dilakukan wawancara kepada para pedagang, penyedia jasa, produser barang yang merupakan masyarakat Desa Cintaratu. Data yang diperoleh meliputi target sasaran, supplier barang, distributor, jaringan komunikasi, proses pengolahan, alat dan bahan yang digunakan, hingga pemasaran produk. Data yang diperoleh diolah untuk diidentifikasi bagaimana jaringan komunikasi ekonomi non-ekstraktif berlangsung di Desa Cintaratu.

Selain itu, pada tahap kegiatan ini dilakukan analisa usaha menggunakan metode Bussines Model Canvas (Djuwendah dan Mujaddid. 2019). Metode Bussines Model Canvas sebagai salah satu studi kasus kegiatan ini menggunakan kegiatan usaha di BUMDes, kepada badan penyuluhan pertanian, dan ketua Gapoktan Desa Cintaratu. Survei lapangan digunakan untuk mempermudah mendapatkan data dan informasi. Selain melakukan survei lapangan, dilakukan juga wawancara kepada beberapa pihak terkait yang dapat memberikan informasi tersebut seperti petani, peternak, dan pembudidaya ikan. Beberapa variabel yang ditanyakan meliputi pola jaringan komunikasi dari satu pihak ke pihak lain, supplier bibit, pupuk, benih, bahan-bahan yang digunakan, proses pembuatan produk. Melakukan FGD dengan beberapa pihak terkait meliputi BUMDes, ketua kelompok tani, pembudi daya ikan, 
dan peternak, kegiatan tersebut bertujuan agar seluruh informasi meliputi saran dan masukan dapat ditampung dan diberikan penyelesaiannya (BUMDes, 2020)

Tahap akhir kegiatan dilakukan pembuatan output kegiatan dan finalisasi data yang telah diperoleh. Kemudian data tersebut disatukan dan dibuat menjadi pembuatan Bussines Model Canvas dan Jaringan Komunikasi Industri Ekonomi Non Ekstraktif.

\section{Hasil dan Pembahasan}

\section{Jaringan Komunikasi Industri Non Ekstraktif di Desa Cintaratu}

Klasifikasi industri berdasarkan bahan baku antara lain: a. Industri Ekstraktif, yaitu industri yang bahan bakunya diperoleh langsung dari alam, seperti pertanian, pertambangan dan perikanan. Industri Ekstraktif dibagi menjadi 2 yaitu : 1) Industri reproduksi, yaitu industri yang bahan bakunya dari alam dan hasil produksinya berupa barang-barang yang baru. 2) Industri manufaktur, yaitu industri yang mengolah bahan baku dan menghasilkan barang yang akan digunakan lagi untuk keperluan industri lain. b. Industri Non Ekstraktif, yaitu industri yang bahan bakunya diperoleh dari kegiatan industri lain. c. Industri Fasilitatif, yaitu industri yang sifatnya memberikan jasa atau fasilitas bagi keperluan orang lain. Berdasarkan Menteri Perindustrian Republik Indonesia Nomor 64 Tahun 2011, klasifikasi industri berdasarkan berdasarkan bahan baku terbagi atas 3 (tiga) jenis yaitu:

(1) Industri ekstraktif, yaitu industri yang bahan bakunya diperoleh langsung dari alam, misalnya; industri hasil pertanian, hasil perikanan dan industri hasil kehutanan. (2) Industri non ekstraktif, yaitu industri yang bahan bakunya berasal dari hasil industri lain (manufaktur). (3) Industri fasilitatif, yaitu industri yang menjual jasa layanan untuk keperluan orang lain, misalnya; perbankan, perdagangan, angkutan dan pariwisata.

Berdasarkan pembagian jenis industri maka terdapat berbagai jenis industri yang ada di Desa Cintaratu. Desa Cintaratu memiliki lima dusun yaitu Dusun Bontos, Cintasari, Sukamanah, Panglanjan, dan Gunung Tiga. Tiap-tiap dusun memiliki potensi dan jenis industri yang berbeda-beda meliputi industri pertanian, peternakan, dan perikanan (industri ekstraktif), maupun industri pengolahan/manufaktur yang mengolah bahan baku hasil industri lain (industri non-ekstraktif), serta jasa, dan perdagangan (industri fasilitatif). Beberapa usaha yag termasuk industri non ekstraktif yang ada di Desa Cintaratu dapat dilihat pada Tabel 1.

Berdasarkan data pada Tabel 1. dapat dilihat bahwa sebagian besar usaha non ekstraktif di Desa Cintaratu, Kecamatan Parigi, Kabupaten Pangandaran adalah produsen makanan yaitu sebanyak $92 \%$, sedangkan produsen gitar dan meubel masing-masing hanya $4 \%$. Industri pengolahan yang memanfaatkan hasil atau bahan baku dari industri lainnya berupa kayu, kayu lapis, onderdil gitar, lem, cat dan lain sebagainya adalah perusahaan produsen gitar listrik. Perusahaan ini bekerjasama dengan pabrik lain dalam memproduksi gitar listrik. Perusahaan hanya memproduksi gitar tanpa merek, kemudian dijual ke pabrik lain. Pemasaran produk dilakukan untuk wilayah Pangandaran dan Semarang, bahkan pernah menjual untuk konsumen dari Kanada.

Meubel Jatnika juga memproduksi berbagai jenis meubeler kebutuhan rumah tangga. Bahan baku berasal dari produksi industri lain, seperti kayu, busa, kain, paku, cat, dan lain-lain. Perusahaan Meubel Jatnika memproduksi berbagai jenis meubeler seperti sofa, lemari, springbed, tempat tidur, dan pohon hias. Konsumen utama perusahaan ini adalah masyarakat sekitar Desa Cintaratu, kecamtan Parigi, dan masyarakat diluar Pangandaran. Usaha meubel ini merupakan usaha warisan dari orang tuanya terdahulu. Permodalan asalnya bersumber dari perbankan kemudian di lunasi dan saat ini modal usahanya merupakan modal usaha sendiri. Kendala yang dihadapi saat ini adalah penjualan cenderung menurun seiring dengan semakin banyaknya pesaing dari luar daerah yang berjualan barang sejenis.

Sebagian besar usaha yang mengubah bahan baku menjadi produk jadi atau produk lainnya adalah usaha produksi makan. Produk makanan yang diproduksi berupa keripik pisang dan keripik ubi yang dihasilkan oleh Kelompok Wanita Tani Binangkit, gorengan dan minuman, makaroni dan keripik, nasi, ikan, bubur, bakso, dan lain sebagainya. Berbagai jenis makanan ini diproduksi oleh sebagian besar jenis usaha yang berada di Desa Cintaratu, Kecamatan Parigi, Kabupaten Pangandaran. Jenis usaha ini tersebar diseluruh dusun yang ada. Sebagian besar bersekala kecil kecuali Rumah Makan Saung Palupuh. Bahan baku yang diproses berasal dari pasar-pasar yang berada di dekat dengan Desa Cintaratu seperti pasar Parigi dan pasar Cibenda. Pasar yang menjadi target usaha 
makanan terutama untuk masyarakat sekitar tempat usaha. Link terbentuk untuk mengkoordinasikan kegiatan yang terjadi di KWT Binangkit. Link dimulai dari ketua sebagai aktor ke seluruh klik yang memiliki fungsi yang berbeda-beda. Link merupakan suatu hubungan yang menghubungkan jaringan jaringan tertentu dengan pola tertentu (Sulistyawati, 2018). Klik 1 memiliki fungasi sebagai bagian produksi, klik 2 bagian packaging, dan klik ke 3 sebagai kelompok pemasaran. Di organisasi ini tiap-tiap klik masih memiliki hubungan. Mereka saling membantu pada semua proses produksi. Hubs merupakan aktor yang paling banyak memiliki jaringan di dalam kelompok tersebut, oleh karena itu ketua KWT Binangkit dapat dikatakan sebagai hubs pada kelompok ini. Ketua kelompok KWT juga berperan sebagai cutpoints karena ketua berperan sebagai pemersatu antar kelompok agar jaringan komunikasinya berjalan dengan baik. Pada kelompok ini tidak terdapat isolate yang memencilkan diri tanpa berkomunikasi dengan yang lainnya.

\section{Implementasi Bussines Model Canvas (BMC)}

BMC adalah bussinnes plan yang formatnya diinovasi menjadi hanya satu halaman yang dibagi menjadi 9 blok masing-masing berisi 9 elemen esensial untuk merencanakan start-up maupun business development. Sembilan elemen dasar dalam mendesain bisnis model dan pengembangan bisnis ini meliputi Customer Segment, Value Propositions, Channels, Customer Relationships, Revenue Streams, Key Resources, Key Activities, Key Partnerships dan Cost Structures. Berdasarkan hasil analisis, maka dapat dibuat konsep BMC yang terdiri atas sembilan elemen tersebut. Berikut adalah uraian 9 elemen dasar pada Usaha BUMDes yang ada di Desa Cintaratu:

a. Customer Segment adalah customer yang dituju yaitu masyarakat yang berusia 17-65 tahun, ibuibu yang mempunyai warung di sekitar kampus Unpad, pengelola bodyrafting di Desa Cintaratu.

b. Value Propositions adalah solusi yang ditawarkan untuk menyelesaikan permasalahan dan memenuhi kebutuhan dari customer yang dituju customer segment. Value bisa berupa kebaruan (news), perbaikan performa berkesinambungan (performent) dan lain sebagainya. Pada BUMDes ini value propositions yang ditawarkan yaitu bagi hasil yang lebih menguntungkan, memermudah masyarakat, fasilitas selalu dilengkapi dan dekat Kampus Unpad, untuk BRI Link biaya transfer lebih murah. c. Channels adalah bagaimana usaha menyampaikan penawaran produknya ke segmen yang dituju dalam hal ini mencakup saluran komunikasi, saluran distribusi dan saluran penjualan. Pada BUMDes, channel yang digunakan yaitu melalui Komunitas Masyarakat Pariwisata (Kompepar), Direct Selling, konter Qillacell milik Bapak Aep.

d. Customer Relationships adalah cara usaha berinteraksi dengan segmen yang dituju yaitu bisa dilakukan dengan menghubungi via whatsapp atau telepon kepada BUMDes.

e. Revenue Streams adalah bagaimana sistem aliran pemasukan dan sistem penentuan harga dari semua kegiatan di elemen value propositions dan key activities. Pada usaha milik BUMDes sendiri yaitu presentase bagi hasil pelampung $80 \%$, presentase bagi hasil BRI Link 60\% dan penyewaan kantin Rp. 300.000 per bulan.

f. Key Activities adalah aktivitas utama untuk menjalankan bisnis. Aktivitas yang ada pada BUMDes berupa penyewaan kantin di kampus Unpad dan penanaman modal.

g. Key Resources mendeskripsikan sumber daya yang paling penting dibutuhkan di sebuah usaha untuk dapat mengoperasikan semua elemen. Pada usaha milik BUMDes, key resources terdiri dari karyawan BUMDes, tukang kuli bangunan, perlengkapan fasilitas bangunan kantin, pelampung, operator, mesin edc, pengelolaan bodyrafting Desa Cintaratu.

h. Key Partnerships adalah partner utama dari usaha yang sangat dibutuhkan untuk beroperasi. Pada usaha milik BUMDes ini bekerjasama dengan Pemerintah Daerah, Kontraktor, Unpad, Toko peralatan, Karang Taruna, Kompepar, Bank BRI.

i. Cost Structures adalah elemen yang mendeskripsikan semua pembiayaan operasional. Biaya pada usaha milik BUMDes sendiri yaitu biaya pembangunan kantin Rp. 30.000.000, biaya pelampung Rp. 28.080.000, biaya BRI Link Rp. 25.000.000. 
Tabel 1. Daftar Industri Non Ekstraktif di Desa Cinta Ratu, Kecamatan Parigi, Kabupaten Pangandaran

\begin{tabular}{|c|c|c|c|c|}
\hline No & Jenis/Nama Usaha & Produk & Lokasi & $\begin{array}{l}\text { Tokoh/ } \\
\text { Pemilik }\end{array}$ \\
\hline 1 & Produsen Gitar & Gitar Listrik & $\begin{array}{l}\text { Dusun } \\
\text { Panglanjan }\end{array}$ & Yayan \\
\hline 2 & Produsen Meubel "Jatnika" & Lemari, kursi, meja & $\begin{array}{l}\text { RT } 8 \text { RW } 8 \\
\text { Dusun Cintasari }\end{array}$ & Jumali \\
\hline 3 & $\begin{array}{l}\text { Produksi makanan } \\
\text { Kelompok Wanita Tani } \\
\text { "Binangkit" }\end{array}$ & $\begin{array}{l}\text { Keripik pisang dan keripik } \\
\text { ubi }\end{array}$ & $\begin{array}{l}\text { Dusun } \\
\text { Panglanjan }\end{array}$ & Tati \\
\hline 4 & $\begin{array}{l}\text { Produksi Makanan Warung } \\
\text { Makanan Kecil }\end{array}$ & Gorengan, minuman, & Dusun Bontos & $\begin{array}{l}\text { Dasini/Hj } \\
\text { Ade } \\
\text { Mulyadi }\end{array}$ \\
\hline 5 & $\begin{array}{l}\text { Produksi Makanan Rumah } \\
\text { Makan "Saung Talupuh" }\end{array}$ & $\begin{array}{l}\text { Nasi (liwet, putih), Ikan } \\
\text { (goreng, bakar, pepes), } \\
\text { ayam (goreng, bakar, } \\
\text { pepes), cah kangkung, } \\
\text { mendoan }\end{array}$ & $\begin{array}{l}\text { RT } 1 \text { RW } 9 \\
\text { Dusun Bontos }\end{array}$ & $\begin{array}{l}\text { Memed } \\
\text { Suhendra }\end{array}$ \\
\hline 6 & $\begin{array}{l}\text { Produksi Makanan Warung } \\
\text { Makanan Kecil }\end{array}$ & gorengan, minuman dingin & $\begin{array}{l}\text { RT } 1 \text { RW } 9 \\
\text { Dusun Bontos }\end{array}$ & $\begin{array}{l}\text { Winda } \\
\text { Kusmah }\end{array}$ \\
\hline 7 & $\begin{array}{l}\text { Produksi Makanan Warung } \\
\text { Makanan Kecil }\end{array}$ & $\begin{array}{l}\text { gorengan, lontong, } \\
\text { minuman dingin }\end{array}$ & $\begin{array}{l}\text { RT } 2 \text { RW } 9 \\
\text { Dusun Bontos }\end{array}$ & Oom \\
\hline 8 & $\begin{array}{l}\text { Produksi Makanan Warung } \\
\text { Nasi }\end{array}$ & Sayur, tumis, sosis, seblak & $\begin{array}{l}\text { RT } 2 \text { RW } 9 \\
\text { Dusun Bontos }\end{array}$ & Teh Olis \\
\hline 9 & $\begin{array}{l}\text { Produksi Makanan } \\
\text { Makaroni }\end{array}$ & $\begin{array}{l}\text { Makaroni, Keripik pisang } \\
\text { kepok }\end{array}$ & $\begin{array}{l}\text { RT } 3 \text { RW } 9 \\
\text { Dusun Bontos }\end{array}$ & $\begin{array}{l}\mathrm{Ai} \\
\text { Kuswati }\end{array}$ \\
\hline 10 & $\begin{array}{l}\text { Produksi Makanan Warung } \\
\text { Makanan Kecil }\end{array}$ & $\begin{array}{l}\text { gorengan, lontong, } \\
\text { mendoan, tahu, kopi }\end{array}$ & $\begin{array}{l}\text { RT } 8 \text { RW } 8 \\
\text { Dusun Cintasari }\end{array}$ & Rokayah \\
\hline 11 & $\begin{array}{l}\text { Produksi Makanan Mie } \\
\text { Ayam }\end{array}$ & $\begin{array}{l}\text { baso, mie ayam, seblak, } \\
\text { soteng, minuman }\end{array}$ & $\begin{array}{l}\text { RT } 2 \text { RW } 7 \\
\text { Dusun Cintasari }\end{array}$ & Cici \\
\hline 12 & $\begin{array}{l}\text { Produksi Makanan Kupat } \\
\text { Tahu dan Bengkel Motor }\end{array}$ & $\begin{array}{l}\text { kupat tahu, soto, karedok, } \\
\text { gorengan, kopi }\end{array}$ & $\begin{array}{l}\text { RT } 2 \text { RW } 7 \\
\text { Dusun Cintasari }\end{array}$ & Hera \\
\hline 13 & $\begin{array}{l}\text { Produksi Makanan Rumah } \\
\text { Makan "Cilempay" }\end{array}$ & $\begin{array}{l}\text { ikan (goreng, bakar, sayur) } \\
\text { nasi, tumis }\end{array}$ & $\begin{array}{l}\text { RT } 8 \text { RW } 8 \\
\text { Dusun Cintasari }\end{array}$ & Yahya \\
\hline 14 & $\begin{array}{l}\text { Produksi Makanan Warung } \\
\text { Nasi }\end{array}$ & $\begin{array}{l}\text { gorengan, soto, karedok, } \\
\text { kupat tahu, sembako }\end{array}$ & $\begin{array}{l}\text { RT } 7 \text { RW } 8 \\
\text { Dusun Cintasari }\end{array}$ & Heni \\
\hline 15 & $\begin{array}{l}\text { Produksi Makanan Es Mie } \\
\text { Ramen \& Es Kepal Milo }\end{array}$ & $\begin{array}{l}\text { es kepal milo, es mie } \\
\text { ramen, pop ice, nugget, } \\
\text { sosis }\end{array}$ & $\begin{array}{l}\text { RT } 7 \text { RW } 8 \\
\text { Dusun Cintasari }\end{array}$ & $\begin{array}{l}\text { Eti } \\
\text { Rohayati }\end{array}$ \\
\hline 16 & $\begin{array}{l}\text { Produksi Makanan Warung } \\
\text { Makanan Kecil }\end{array}$ & $\begin{array}{l}\text { otak-otak, empek-empek, } \\
\text { es campur, aneka jus }\end{array}$ & $\begin{array}{l}\text { RT } 7 \text { RW } 8 \\
\text { Dusun Cintasari }\end{array}$ & Tovia \\
\hline 17 & $\begin{array}{l}\text { Produksi Makanan Warung } \\
\text { Nasi }\end{array}$ & nasi, tumis, sayur & $\begin{array}{l}\text { RT } 3 \text { RW } 4 \\
\text { Dusun } \\
\text { Sukamanah }\end{array}$ & Enceng \\
\hline 18 & $\begin{array}{l}\text { Produksi Makanan Warung } \\
\text { Surabi \& Makanan Kecil }\end{array}$ & cireng, surabi, gorengan & $\begin{array}{l}\text { RT } 6 \text { RW } 5 \\
\text { Dusun } \\
\text { Sukamanah }\end{array}$ & Idah \\
\hline
\end{tabular}




\begin{tabular}{|c|c|c|c|c|}
\hline 19 & $\begin{array}{l}\text { Produksi Makanan Warung } \\
\text { Makanan Kecil }\end{array}$ & otak-otak, sosis & $\begin{array}{l}\text { RT } 4 \text { RW } 5 \\
\text { Dusun } \\
\text { Sukamana }\end{array}$ & Isoh \\
\hline 20 & $\begin{array}{l}\text { Produksi Makanan Nasi } \\
\text { Goreng, Martabak \& } \\
\text { Gorengan }\end{array}$ & $\begin{array}{l}\text { gorengan, chicken, nasi } \\
\text { goreng, martabak }\end{array}$ & $\begin{array}{l}\text { RT } 4 \text { RW } 4 \\
\text { Sukamanah }\end{array}$ & Riki \\
\hline 21 & $\begin{array}{l}\text { Produksi Makanan Bubur } \\
\text { Ayam } 24 \text { Jam }\end{array}$ & $\begin{array}{l}\text { bubur ayam, bubur } \\
\text { kacang, ketan hitam, mie } \\
\text { rebus, mie goreng }\end{array}$ & $\begin{array}{l}\text { RT } 4 \text { RW } 4 \\
\text { Sukamanah }\end{array}$ & Karmah \\
\hline 22 & $\begin{array}{l}\text { Produksi Makanan Sate } \\
\text { Ayam \& Sate Sapi }\end{array}$ & Sate ayam, sate sapi & $\begin{array}{l}\text { RT } 4 \text { RW } 5 \\
\text { Dusun } \\
\text { Sukamana }\end{array}$ & Nurahayati \\
\hline 23 & $\begin{array}{l}\text { Produksi Makanan Warung } \\
\text { Makanan Kecil }\end{array}$ & $\begin{array}{l}\text { kopi, minuman, sosis, mie } \\
\text { goreng, mie rebus, otak- } \\
\text { otak, tahu bulat, jus honje, } \\
\text { jus markisa }\end{array}$ & $\begin{array}{l}\text { RT } 4 \text { RW } 5 \\
\text { Dusun } \\
\text { Sukamana }\end{array}$ & Nurlaela \\
\hline 24 & $\begin{array}{l}\text { Produksi Makanan Warung } \\
\text { Nasi }\end{array}$ & $\begin{array}{l}\text { nasi, tumis, sayur, ayam } \\
\text { goreng, ayam balado }\end{array}$ & $\begin{array}{l}\text { RT } 6 \text { RW } 5 \\
\text { Dusun } \\
\text { Sukamanah }\end{array}$ & Yanti \\
\hline 25 & $\begin{array}{l}\text { Produksi Makanan Warung } \\
\text { Nasi Padang }\end{array}$ & $\begin{array}{l}\text { nasi padang, rendang, } \\
\text { ayam, perkedel }\end{array}$ & $\begin{array}{l}\text { RT } 4 \text { RW } 5 \\
\text { Dusun } \\
\text { Sukamana }\end{array}$ & Selly \\
\hline 26 & $\begin{array}{l}\text { Produksi Makanan Ayam } \\
\text { Bakar\&Ayam Goreng }\end{array}$ & $\begin{array}{l}\text { Nasi uduk, ayam bakar, } \\
\text { ayam goreng, lumpia } \\
\text { basah }\end{array}$ & $\begin{array}{l}\text { RT } 4 \text { RW } 5 \\
\text { Dusun } \\
\text { Sukamana }\end{array}$ & Ervan \\
\hline 27 & $\begin{array}{l}\text { Produksi Makanan Bakso } \\
\text { Tasik }\end{array}$ & $\begin{array}{l}\text { mie baso, mie ayam, es } \\
\text { jeruk }\end{array}$ & $\begin{array}{l}\text { RT } 5 \text { RW } 2 \\
\text { Dusun } \\
\text { Panglanjan }\end{array}$ & Hera \\
\hline
\end{tabular}

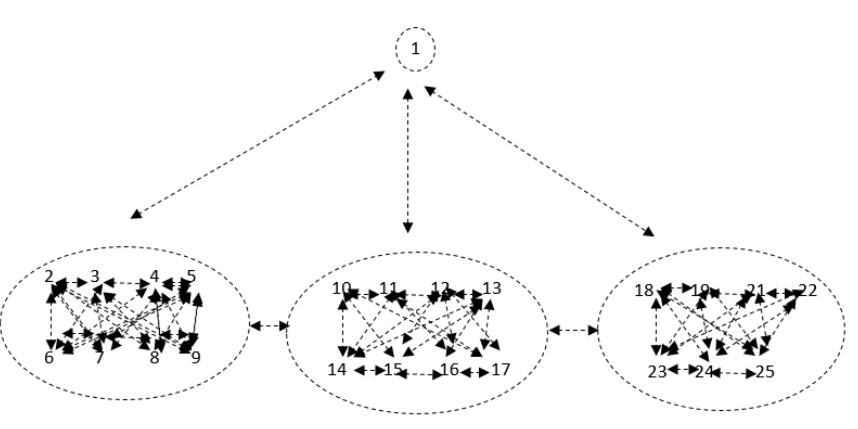

Gambar 1. Jaringan Komunikasi di Kelompok Wanita Tani Biangkit

\section{Kesimpulan}

Secara umum, jaringan komunikasi pada industri non ekstraktif di Desa Cintaratu, Kecamatan Parigi, Kabupaten Pangandaran belum terjalin dengan baik. Mereka masih melakukan usaha secara sendiri sendiri, belum terjadi konektivitas diantara pelaku usaha. Jaringan komunikasi baru terjalin di
Kelompok Tani Wanita Binangkit, jaringan terbentuk diantara anggota kelompoknya saja. Di KWT Binangkit yang menjadi aktornya adalah ibu Tati sebagai ketua kelompok,selain menjadi aktor Ibu Tati juga menjadi hubs yang merekatkan kegiatan di kelompok ini.

Masih banyak potensi usaha yang dapat dikembangkan di Desa Cintaratu. Salah satu usaha tersebut adalah Badan Usaha Milik Desa (BUMDes) Cintaratu yang memiliki unit-unit usaha, yaitu penyewaan pelampung Jojogan, BRI Link, Penyewaan Kantin Unpad Cintaratu. Unit usaha tersebut dapat dikembangkaan dengan menggunakan Business Model Canvas.Customer BUMDes adalah usia produktif dan pemiliki usaha, Value yang ditawarkan adalah saling menguntungkan, mempermudah, dan fasilitatif bagi konsumen, channel yang digunakan yaitu melalui komunitaas, direct selling. Revenue Streams didapat dari presentase bagi hasil dan penyewaan toko. Key Activities berupa penyewaan kantin dan penanaman modal. Key Resources terdiri dari karyawan, 
perlengkapan, dan fasilitas usaha, Key Partnerships bekerjasama dengan Pemerintah Daerah, Kontraktor, Unpad, Toko peralatan, Karang Taruna, Kompepar, Bank BRI, Cost Structures yang ada adalah biaya investasi, modal kerja, dan operasional.

\section{Ucapan Terimakasih}

Kami menngucapkan terimakasih yang sebesar-besarnya kepada Rektor Universitas Padjadjaran yang telah mendanai kegiatan ini dalam program KKN Kewirausahaan Tahun Anggaran 2020. Terimakasih juga kami ucapkan kepada mahasiswa KKN-Kewirausahaan PSDKU Pengandaran kelompok 11 periode KKN Bulan Januari - Februari 2020.

\section{Daftar Pustaka}

Borgatti, Stephen P. dan Rich Dejody, 2013. "Basic Concepts in Social Network Analiysis" Makalah Workshop SNA, 5 Juni 2013. Diakses dari https://sites.google.com/site/uklinkcenter

BUMDes. 2020. Dokumen BUMDes Desa Cintaratu Pangandaran. Kantor Desa Cintaratu.

Djuwendah, E. dan A. Mujaddid. 2019. Pengembangan Strategi Bisnis Dodol Garut Menggunakan Kanvas Model Bisnis (Studi Kasus pada PD Katineung Kabupaten Garut). Jurnal Ilmu Pertanian dan Peternakan. Vol 7 (1): 1-11

Edy Haryono. 2004. Geografi Industri. FKIP Unila. Bandar Lampung.

Golbeck, J. 2013. Analyzing the Social Web. Boston. Elsevier.

Kotler. 2002. Marketing Management, Analysis, Planning, Implementation, and Control. PrenticeHall International.

Muhammad, A. 2004. Komunikasi Bisnis. Jakarta: Bumi Aksara

Mulyana, D. 2005. Ilmu Komunikasi: Suatu Pengantar. Bandung Remaja Rosdakarya

Mutaqin, B.K., R.F. Christi dan J. Gumilar. 2020. Pemetaan ketahanan jaringan komunikasi ekonomi nonekstraktif di desa cintaratu pangandaran. Jurnal Pengabdian Masyarakat Peternakan. 5 (1): 60-66

Nusantara, A.F. 2017. Pengukuran Peta Bidang Tanah
Calon Kampus Program Studi Di Luar Kampus Utama Universitas Padjajaran Desa Cintaratu Kecamatan Perigi Kabupaten Pangandaran.

http://repository.upi.edu/32103/4/TA PIG 14056 33_Chapter1.pdf

Scott, Noel, Rodolfo Baggio and Chris Cooper. 2008. Network Analysis and Tourism : From Theory to Practice. Toronto.Channel View Publications.

Sulistiawati. A., 2018. Analisa Jaringan Komunikasi Tingkat Kelompok dalam Gapoktan. Jurnal Sains Komunikasi dan Pengembangan Masyarakat (JSKPM), 2(2): 155-168.

DOI: https://doi.org/10.29244/jskpm.2.2.155-168

Tjiptono, F. 2008. Strategi Pemasaran. Yogyakarta: Andi

Utami, A.B., 2018. Analisis Jaringan Komunikasi Kelompok. Conference on Dynamic Media, Communications, and Culture. MCC Conference Proceeding, Vol. 1. 